Review Article

\title{
CONSERVATIVE TECHNIQUE OF PLACENTA ACCRETA SPECTRUM DISORDER (PASD)
}

\author{
DESYHANDAYANI A. F. S. ${ }^{1}$, MUARA P. LUBIS 2
}

1Departement of Obstetrics and Gynecology, Medical Faculty, Universitas Sumatera Utara, General Hospital Haji Adam Malik Medan, Indonesia, ${ }^{2}$ Feto Maternal Division, Department of Obstetrics and Gynecology, Medical Faculty, Univesitas Sumatera Utara, General Hospital Haji Adam Malik Medan, Indonesia Email: desyhandayaniafs718@gmail.com

Received: 15 Mar 2020, Revised and Accepted: 19 May 2020

\begin{abstract}
This article review was aimed to discuss about the choices of conservative technique of placenta accrete spectrum disorder. Placenta Accreta Spectrum Disorder (PASD) is an obstetric complication complexes which tend to cause high maternal morbidity. Maternal morbidity has been reported in $60 \%$ of cases and mortality reaches $7 \%$ in women with placenta accreta. Internationally, the incidence of abnormal placental invasion has increased in the last $30 \mathrm{y}$ and is currently reported to occur in 2-90 per 10,000 deliveries. Main cause of PASD is uterine surgery in particular, scars from cesarean section, a 56-fold increase in risk after three times cesarean section. In cases without massive bleeding and coagulopathy, a conservative approach can be considere. Four main conservative management methods have been described in several international literature, namely extirpative techniques (manual removal of the placenta); leaving the placenta in situ or an observative approach; one-step conservative operation (removal of the location of the accreta; and Triple-P procedure (stitching around the accretion area after resection).
\end{abstract}

Keywords: Conservative technique, Placenta accrete

(C) 2020 The Authors. Published by Innovare Academic Sciences Pvt Ltd. This is an open access article under the CC BY license (http://creativecommons.org/licenses/by/4.0/] DOI: http://dx.doi.org/10.22159/ijcpr.2020v12i4.39094. Journal homepage: https://innovareacademics.in/journals/index.php/ijcpr

\section{INTRODUCTION}

Abnormal placental adhesions can be classified into three different conditions namely placenta accreta, in which placental tissue invades myometrialdecidual surface; increta placenta, placental villi invade deep myometrium, and percreta placenta which is chorionic villi penetrate uterine serosa and can invade surrounding organs such as the bladder [1].

The incidence of placenta accreta is likely to continue to increase. A case-control study in China showed that the incidence of morbidly adherent placenta/MAP was 1.7 per 10,000 deliveries and that proportion increased to 577 per 10,000 deliveries among pregnant women with placenta previa and a history of previous cesarean section [2]. Incidence in Indonesia since 2016 reached $2 \%$ and is still increasing today. A study in Surabaya in 2018 showed the incidence of placenta accreta at RSUD Dr. Soetomo Surabaya was 4\% [3].

About $95 \%$ of women who experience PAS disorders during labor have a history of at least one previous cesarean section and the most common presentation is placenta previa accrete [4, 5]. Previous studies found the relationship between PASD and previous cesarean sections ranging from a sevenfold increase in risk after one cesarean section to 56-fold increase in risk after three cesareans. Overall, the odds ratio for placenta accreta with a history of uterine surgery was 3.40 (95\% CI 1.30-8.91) [1,6].

Conservative management of morbidly adherent placenta (placenta accreta) and invasive placenta (placenta increta and percreta) includes all procedures aimed at avoiding peripartum hysterectomy, morbidity and related consequences. Four main conservative management methods have been described in several international literature, namely extirpative techniques (manual removal of the placenta); leaving the placenta in situ or an observative approach; one-step conservative surgery (removal of the site of the accreta; and Triple-P procedure (suturing around the accretion area after resection). The main goal of leaving the placenta in situ compared to the extirpative method is to reduce the risk of maternal morbidity during cesarean birth [7].

In a cohort study of 68 women with invasive placenta in adjacent organs including posterior upper bladder invasion $(n=46$; group 1$)$ or lower posterior vesical section $(n=22$; group 2$)$, after conservative one-step management, the uterus was successfully maintained in 44 of 46 cases (95.7\%) and 6 of $22(27.3 \%)$ cases, respectively. In addition, a recent prospective study of 71 patients with placenta percreta evaluated a variety of stepwise approaches and found that the procedure was successful in controlling bleeding and maintaining the uterus in 65 cases $(91.5 \%)$. Comparison of the two periods (ie before [ $n=11]$ and after $[n=19]$ implementation of the Triple-P procedure) did not show significant differences in mean blood loss and transfusion rates; however, rates of postpartum hemorrhage and hysterectomy were shown to be lower in the Triple-P procedure group [7]. Another study about placenta accreta in which nineteen patients underwent partial management of left in situ placenta, while 2 patients with complete placenta left in situ, was found that conservative management was successful in 15 patients, and the uterus was successfully maintained in these patients [8].

It appears that the incidence of placenta accreta spectrum is increasing every years, then significant morbidity and mortality affect the lives of patients especially for fertility problems. However, it has been found conservative management in placenta accrete case for avoid hysterectomy in patients so they can maintain the uterus and female fertility. Therefore, the writer is interested to make an article review about conservative management on the placenta accreta spectrum.

\section{Article review}

Placenta accreta was first discovered in 1937 by Irving et al. as a condition of failure to separate the placenta from the uterine wall when labor which refers to morbidly adherent placenta (MAP). Various terms have been applied to this condition; However, the latest guidelines approved the use of the term Placenta Accreta Spectrum Disorder (PASD), which includes accreta, increta and percreta (defined below) for this condition [9].

The average maternal age is around $34 \mathrm{y}$ and the median parity is 2.5. The risk of developing placenta accreta increases with number of previous cesarean births. Incidence ranges from $2 \%$ among women with placenta previa up to $39-60 \%$ among women with a history of cesarean section $>2$ times and up to $88 \%$ in women who have both of these risk factors. Risk factors besides history of cesarean section issubmucosalmyoma, history of curettage, 
Asherman syndrome, advanced maternal age, grandemultiparity, smoking, and chronic hypertension. Alanis et al. reviewed 72 cases of placenta accreta treated conservatively. Between $15 \%$ of women who have subsequent pregnancies, $18 \%$ experience recurrence placenta accreta, so a previous history of placenta accreta is possible as a major risk factor [11].

Table 1: Classification of placenta accrete [10] based on the degree of invasion

\begin{tabular}{lll}
\hline Grade & Histologic criteria \\
\hline 1 & $\begin{array}{l}\text { Placenta adherenta } \\
\text { or creta } \\
\text { Increta }\end{array}$ & $\begin{array}{l}\text { Placental bed samples from hysterectomy specimen shows extended areas of absent decidua between villous } \\
\text { tissue and myometrium with placental villi attached directly to the superficial myometrium }\end{array}$ \\
& $\begin{array}{l}\text { Hysterectomy specimen or partial myometrial resection of the increta area shows placental villi within the } \\
\text { muscular fibers and sometimes in the lumen of the deep uterine vasculature (radial or arcuate arteries) }\end{array}$ \\
& Percreta & $\begin{array}{l}\text { 3A-Hysterectomy specimen showing villous tissue within or breaching the uterine serosa } \\
\text { 3issue or urothelium }\end{array}$ \\
& & 3C-Hysterectomy specimen showing villous tissue breaching the uterine serosa and invading pelvic tissue/organs \\
& &
\end{tabular}

\section{Pathogenesis}

The pathogenesis hypothesis of placenta accreta is associated with abnormal development of decidua, excessive invasion of trophoblasts, or a combination of both. Decidualization defects, abnormal remodeling of maternal blood vessels, excessive invasion of trophoblasts, or a combination of both are considered as consequences of previous actions [11]. Wihout endometrial reepithelialization in the scar area, trophoblasts and villous tissue can invade into myometrial tissue, including circulation and reach the surrounding pelvic organs. Cellular changes in the trophoblast observed in the placenta accreta spectrum may be secondary to myometrial abnormalities during placental development, and not due to biological defects of the trophoblast that trigger excessive over invasion of the myometrium [12].

\section{Classification}

Classification of placenta accreta based on the invasion is: [1] Placenta accreta: trophoblast cells attach to the surface of myometrium without decidual layer [2]. Placenta increta: trophoblast cells invade into the myometrium [3]. Placenta percreta: trophoblast cells invade the serous lining of uterus $[1,12]$.

\begin{abstract}
Diagnostic
Ultrasound as a diagnostic modality for placenta accreta has high sensitivity with $91 \%$, positive predictive value $80 \%$ and negative predictive value $98 \%$. A pregnant woman should have a mass screening during pregnancy against the risk of placenta accreta since the first trimester or the second trimester of pregnancy [13]. There are several scoring for placenta accreta screening namely the Placenta Accreta Index Score (PAI Score) [14].

On ultrasound examination, there will appear several images such as lacunae which has irregular images, rarely spherical in shape and more like moth eaten, sometimes appears turbulent blood flow, such as a tornado vortex, although not $100 \%$ found in every case. Irregularity border between myometrium and vesika urinary with protrusion of trophoblast toward the urinary bladder is often seen in placenta acceta. It also found myometrium thickness $<1$ $\mathrm{mm}$. On ultrasound examination, the hyperechoic region behind the placenta is bordered by myometrium which is a reflection of the decidual basal region. Vascular features that originate in the placenta, cross over the retroplacental area toward the bladder or tissue surrounding the uterus are characteristic of placenta accrete [15-17].
\end{abstract}

Table 2: Placenta accreta spectrum disorder classification [18] based on ultrasound examination results

\begin{tabular}{|c|c|c|c|}
\hline US stage of PAS disorder & US finding & Histopathology & FIGO grade \\
\hline PAS 0 & $\begin{array}{l}\text { Placenta previa with no ultrasound signs of invasion or } \\
\text { Placenta previa with placental lacunae but no evidence of } \\
\text { abnormal uterus-bladder interface (loss of clear zone } \\
\text { andor bladder wall interruption) }\end{array}$ & Placenta previa without PAS & $1-2$ \\
\hline PAS 1 & $\begin{array}{l}\text { Presence of at least two ultrasound signs among: } \\
\text { : Placenta lacunae } \\
\text { : Loss of clear zone } \\
\text { : Bladder wall interruption }\end{array}$ & Placenta accreta/increta & 3 \\
\hline PAS 2 & PAS 1 plus uterovesicalhypervascularity & Placenta percreta focal or diffuse & $4-5$ \\
\hline PAS 3 & $\begin{array}{l}\text { PAS } 1 \text { or PAS } 2 \text { plus evidence of increased vascularity in } \\
\text { inferior part of lower uterine segment extending into } \\
\text { parametrial region }\end{array}$ & $\begin{array}{l}\text { Placenta percreta invading inferior } \\
\text { third or lower uterine segment and } \\
\text { lateral pelvic walls (or parametria) }\end{array}$ & 6 \\
\hline
\end{tabular}

\section{Management placenta accreta spectrum disorder}

In placenta accreta/increta cases diagnosed within antepartum, the baby must be delivered by elective cesarean section and the possibility that the patient will need a hysterectomy immediately after a cesarean section needs to be discussed with the patient [19]. Many studies have suggested elective labor after $34 \mathrm{w}$ of gestation [20]. The standard therapy for placenta accreta/increta currently diagnosed in postpartum is hysterectomy. However, several reports have found various therapies that can maintain the uterus and fertility [19]. In general, there are two types of placenta accreta management, namely non-conservative and conservative. Nonconservative is a technique that done by removing the uterus or hysterectomy and conservative is a technique to prevent hysterectomy and all its morbidity [21].
There are several methods in conservative techniques, namely Extirpative Technique which is a procedure of manually removing the placenta during surgery. The aim of this procedure is to prevent the retention of placental tissue in uterine cavity, because it is a source of postpartum hemorrhage. Complications of bleeding in placenta extirpation is quite a lot so it is not recommended except for placenta accreta with less severe invasion [21].

Leave placenta in situ is a procedure that done by leaving the placenta in place without disturbing the placenta with the aim of being absorbed completely in the future. It is expected that there will be a decrease in blood circulation and cause villous tissue necrosis and the placenta will escape independently of the uterus and villi precreta from the attached organ. Leaving the placenta in situ was initially done in cases with high complications of 
hysterectomy cesarean section, especially those at risk of massive bleeding, for example in the placenta attached to wide place or up to parametrium [21, 22].

There are additional methods performed by leaving the placenta in situ ie bilateral uterine artery ligation significantly reduces bleeding caused by uterine inertia and abnormal placentation. Perfusion reduction procedures include non-surgical and surgical procedures. Bilateral uterine artery ligation is not permanent but significantly decreases arterial flow. After that, blood vessel recanalization will begin and restore the previous blood flow and maintain fertility function. Uterine artery ligation is the first choice in $92 \%$ of cases with a complication rate around 1\% [23].

A high-limit transverse uterine incision above placenta was done to avoid transplacental incision that triggers heavy bleeding and then extraction of the baby with ecbolic administration. Double uterine artery ligation on both sides (DUAL) process include ligation before separation of the lower bound placenta at the level uterine isthmus. The second ligature is performed after separation of the high-limit placenta at the level uteroovarian anastomosis. Removal of the placenta, both total and part of the placenta is removed according to the level of placental invasion. Hemostatic "quadratic" quadruple sutures in lower uterine segments at points of bleeding and even suturing the placental base. Insertion of triple way Foley catheter with size $24 \mathrm{~F}$ by filling $50 \mathrm{cc}$ of saline to suppress the bleeding point in the lower uterine segment. Closure of the uterine wall incision with a continuous double layer, the first layer to reduce bleeding significantly, the second layer to the tightness of the suture [24].

In recent observation of 24 women with PAS disorders who were left in situ after birth and were treated with methotrexate $(100 \mathrm{mg}$ intramuscularly immediately postpartum), placental delivery was reported in $33.3 \%$ of cases (spontaneously in $55 \%$ and $45 \%$ by dilatation and curettage). In addition, beta-human chorionic gonadotropin ( $\beta$-hCG) levels and Doppler vascular resistance index of uteroplacental arterial circulation decrease faster than women who fail treatment [7].

One step conservative surgery is a procedure consisting resection of invasive accretion area (partial resection of myometrium) followed by immediate uterine reconstruction and bladder strengthening. The main step in maintaining the uterus in this technique can be done through modified Pfannenstiel or midline incision.7Then dissection posterior bladder wall was done, hysterotomy is performed above the margin of the placenta, the entire placenta and the invading myometrium are removed in one surgical section. In this way, the reconstruction of the uterus is carried out using healthy tissue. Uterine hemostasis is achieved by a pair of box stitches following this technique. With the aim of preventing hematometra, the bougy Hegar No. dilator 10 is placed inside the cervix where it will move to one side. Then repair the uterus in two layers [20].

Double incision technique is a technique that performed if the placenta percreta is not related to previous caesarean section area and bladder dissection can be done with trans placental segmental approach also can be done. Previously a $200 \mathrm{ml}$ saline solution filled the bladder. While dissection is done, ligase from neoformation of blood vessels is performed. After retrovesical chamber dissection, hysterotomy is performed at the top of the segment involved. Myometrium from the placental attachment pathology is incised in an elliptical or diamond shape. The lower part of the incision is made at least $2 \mathrm{~cm}$ from the top of the uterine istmus. Segmental resection is performed and the incision area is closed with multiple z-shaped stitches [25].

However, if there is extensive placental adhesion, transplacenta approach is not possible, then transverse or vertical corporal incision is used to prevent damage to the placenta. After opening the retrovesical space, an elliptical incision is made. The area involved in the placenta is removed (double incision is performed for segmental resection). The first incision for fetal extraction is closed with a single layer interrupted continuous suture and segmental resection is closed with multiple z-shaped stitches [25].

The advantages of Double Incision Technique are: Extraction is safe for the fetus, reducing time lost during vesicouterine dissection and damage of fetoplacenta circulation. Reduces blood loss due to incisions that approach the adhesive placenta. Hysterectomy can be easily done if needed [25].

The triple $\mathrm{P}$ procedure for placenta percreta is 3-step conservative technique in which it covers perioperative localization of the placenta and gives birth to the fetus through a transverse incision in the uterus above the placenta, pelvic devascularization, and placental non-separation with myometrial excision and reconstruction of the uterine wall [26].

This procedure consists of several stages, namely localization of the perioperative placenta and delivery of the placenta where the upper border of the placenta is marked externally, then the abdomen is opened, visualization of the anterior uterine wall is performed and transverse incision was done, $2 \mathrm{~cm}$ above the initial limit, then the high transverse uterine incision is carried out above the upper border placenta without penetrating the placenta. Pelvic devascularization is performed by occlusion with balloon catheter that is placed between the internal iliac arteries of the anterior branch after the fetus is born. If there is no radiological intervention, uterine artery ligase or quadruple ligase can be performed [26].

Placental non-separation by myometrium excision is performed with excision of entire anterior myometrial wall to which the placenta attached, the lateral border is extended to the angle of uterine incision. The upper part can be released from the trophoblast tissue. At the bottom, myometrium is excised up to a horizontal line about $2 \mathrm{~cm}$ above the bladder. After the myometrium has been excised along with the placenta, the lower portion of the former is converted to expose the trophoblast tissue to the posterior wall of the bladder. Multiple hemostatic sutures are performed to prevent bleeding. The uterus is closed with 2 layers of stitches. Then the balloon artery catheter was deflated $4 \mathrm{~h}$ after surgery [26].

\section{Folding sutures followed by tourniquet bindings}

Is a conservative operative approach to placenta previa and morbidly adherent placenta using three steps: localization of the perioperative placenta and delivery of the fetus, tourniquet bindings and placental removal, and folding sutures. Localization of the perioperative placenta was done with incision above the placental limit without crossing the placenta. The fetus is born through a uterine transverse incision above the upper limit of the placenta. When the fetus has been born, uterine blood supply is reduced by using tourniquet around the lower uterine segment. Then, the placenta is released. Partial placenta can be left in situ if the placenta sticks in. After the placenta is released, folding sutures are done in the lower uterine segment [27].

Chromic catgut No. 1 penetrate the posterior wall of the uterus vertically to the anterior wall from the right lateral edge of the lower uterine segment. Stitches are stretched horizontally to the left about 2$3 \mathrm{~cm}$. The gut paint thread is sewn in the posterior and vertical direction, entering the uterine cavity. Stitches are passed towards the back approximately $1-1.5 \mathrm{~cm}$ and are passed anteriorly parallel to the first point of entry. Gut paint is drawn and passed towards the left about $2-3 \mathrm{~cm}$. Stitches are passed vertically to the posterior wall to the left edge of the lower uterine segment. Gut paint is drawn to cause a compression effect. Tourniquet is released and observation of blood from the incision area. Then the uterus is sewn as usual [27].

\section{Nausicaa compression sutures}

Are a technique where after the fetus is born, the uterus is externalized and inspected bleeding then placenta is removed. Uterine compression is used using Vicryl $\AA^{\circledR}$ 1-0 thread. Transfused needles from the lateral serous uterus to the bleeding area (or the invaded myometrium area) toward the uterine cavity. The needle is inserted horizontally into the uterine cavity until it covers the bleeding area, then is blown to the other side of the uterine serosa. Sutures are penetrated into the myometrium without being fastened to the anterior and posterior walls. Performed flat surgical knots tightly. The advantage of this technique is this procedure is relatively simple to perform, compression sutures are performed leaving the cesarean section incision open, and the sutures are not binding between the anterior and posterior uterus together, so that the locia and debris can flow as normal [28]. 


\section{Complication}

Placenta accreta causes massive bleeding, disseminated intravascular coagulation (DIC),, liver and kidney damage and even requires hysterectomy. ${ }^{2}$ Maternal morbidity has been reported in $60 \%$ of cases and mortality reaches $7 \%$ in women with placenta accreta. In addition, the emergence of perinatal complications also increases the risk of morbidity and mortality mainly due to premature birth and small baby weight [11]. Overall, the risk of PAS disorders recurrence ranges between $22 \%$ and $29 \%$, while the risk of postpartum hemorrhage is between $8.6 \%$ and $19 \%$ [7].

\section{CONCLUSION}

Based on FIGO guidelines, conservative management of morbidly adherent placenta (placenta accreta) and invasive placenta (placenta increta and percreta) includes all procedures aimed at avoiding peripartum hysterectomy, morbidity and related consequences. Four main conservative management methods have been described in several international literature, namely extirpative techniques (manual removal of the placenta); leaving the placenta in situ or an observative approach; one-step conservative operation (removal of the accrete area; and Triple-P procedure (stitching around the accretion area after resection).

\section{FUNDING}

Nil

\section{AUTHORS CONTRIBUTIONS}

All the authors have contributed equally.

\section{CONFLICT OF INTERESTS}

Declare none

\section{REFERENCES}

1. Fitzpatrick KE, Sellers S, Spark P, Kurinczuk JJ, Brocklehurst P, Knight M. Incidence and risk factors for placenta Accreta/Increta/Percreta in the UK: a national case-control study. PLOS One 2012;7:1-7.

2. Chen L, Wang X, Wang H, Li Q, Shan N, Qi H. Clinical evaluation of prophylactic abdominal aortic balloon occlusion in patients with placenta accreta: a systematic review and meta-analysis. BMC Pregnancy Childbirth 2019;19:30.

3. Aryananda RA. Resurgence of placenta accrete in Indonesia. Maj Obs Gin 2018;26:98-9.

4. Jauniaux E, Silver RM, Matsubara S. The new world of placenta accrete spectrum disorders. Int J Gynecol Obstet 2018;140:259-60.

5. Jauniaux ERM, Alfirevic Z, Bhide AG, Belfort MA, Burton GJ, Collins SL, et al. Placenta praevia and placenta accreta: diagnosis and management. RCOG Green-Top Guideline 2018;126:1-48.

6. Thurn L, Lindqvist PG, Jakobsson M, Colmorn LB, Klungsoyr K, Bjarnadottir RI, et al. Abnormally invasive placentaprevalence, risk factors and antenatal suspicion: results from a large population-based pregnancy cohort study in the Nordic countries. BJOG 2016;123:1348-55.

7. Sentilhes L, Kayem G, Chandraharan E, Palacios Jaraquemada J, Jauniaux E. FIGO consensus guidelines on placenta accrete spectrum disorders: conservative management. Int J Gynecol Obstet 2018;140:291-8.

8. Zhong L, Chen D, Zhong M, He Y, Su C. Management of patients with placenta accrete in association with fever following vaginal delivery. Medicine 2017;96:10.

9. Bartels HC, Postle JD, Downey P, Brennan DJ. Placenta accreta spectrum: a riview of pathology, molecular biology, and biomarkers. Disease Markers 2018;1-12. DOI:10.1155/2018/1507674

10. Jauniaux E, Campos DA, Roos JL, Fox KA, Collins S. FIGO classification for the clinical diagnosis of placenta accrete spectrum disorders. Int J Gynecol Obstet 2019;146:20-4.

11. Garmi G, Salim R. Epidemiology, etiology, diagnosis, and management of placenta accreta. Obstetrics Gynecol Int 2012:1-7. DOI:10.1155/2012/873929

12. Jauniaux E, Collins S, Burton GJ. Plasenta accrete spectrum: pathophysiology and evidence-based anatomy for prenatal ultrasound imaging. AJOG 2018;218:75-87.

13. Aryananda RA, Akbar A, Wardhana MP. New three dimensional/four dimensional volume rendering imaging software for detecting the abnormally invasive placenta. J Clin Ultrasound JCU 2019;47:9-13.

14. Rac MW, Dashe JS, Wells CE, Moschos E, Melntire DD, Twickler DM. Ultrasound predictors of placental invasion: the placenta accreta index. AJOG 2015;212:341-7.

15. Collins SL, Asheroft A, Braun T. Proposal for standardized ultrasound descriptors of abnormally invasive placenta (AIP). J Int Soc Ultrasound Obstetrics Gynecol 2016;47:271-5.

16. Alfirevic Z, Tang AW, Collins SL, Robson SC, Palacios Jaraquemada J. Group of the proforma for ultrasound reporting in suspected abnormally invasive placenta (AIP). Int Consensus 2016;47:276-8.

17. Silver R. Placenta accreta syndrome. Boca Raton: CRC Press, Taylor and Francis Group; 2017.

18. Cali G, Forlani F, Lees C, Timor I, Palacios Jaraquemada J. Prenatal ultrasound staging system for placenta accreta spectrum disorders. Uktrasound Obstet Gynecol 2019;53:752-3.

19. Peiffer S, Reinhard J, Louwen F. Conservative management of placenta accreta/increta after vaginal birth. Geburtshilfe Freauenheikld 2012;72:940-4.

20. Shehata A. Uterine sparing techniques in placenta accreta. Obstet Gynecol Int J 2016;5:00143.

21. Lisa A, Jauniaux E, Hobson S, Papillon Smith J, Belfort MA. FIGO consensus guidelines on placenta accreta spectrum disorder: nonconservative surgical management. Int J Obstet 2018;140;281-90.

22. Satuan Tugas Plasenta Akreta, Kelainan Spektrum Plasenta Akreta. Kisah Warga Trenggalek Berjuang untuk Istrinya yang Idap Plasenta Akreta, ini Saran untuk Ibu Hamil. HKFM 2019;18:34.

23. Arab M, Ghavami B, Saraeian S, Sheibani S, Azar FA, Hosseini Zijpud SM. Successful management of two cases of placenta accreta and a literature review: use of the b-lynch suture and bilateral uterine artery ligation procedures. Iran Red Crescent Med 2016;18:1-4.

24. Marey DA. Outcome of stepwise uterine sparing approach as a conservative surgical management of placenta accreta. Gynecol Obstet Res Open J 2017;4:36-40.

25. Polat I, Yucel B, Gedikbasi A, Aslan H, Fendal A. The effectiveness of double incision technique in uterus preserving surgery for placenta percreta. BMC Pregnancy Childbirth 2017; 17:129.

26. Chandarahan E, Rao S, Belli A, Arulkumaran S. Triple p procedure as a conservative surgical alternative to peripartum hysterectomy for placenta percreta. IJOG 2012;117:191-4.

27. Yen J, Yen C, Xin H. Folding sutures following tourniquet binding as a conservative surgical approach for placenta previa combined with morbidly adherent placenta. Chin Med J 2015;128:2818-20.

28. Shih JC, Liu KL, Kang J, Yang JH, Lin MW, Yu CU. 'Nausicaa' compression suture: a simple and effective alternative to hysterectomy in placenta accreta spectrum and other causes of severe postpartum haemorrhage. BJOG 2019;126:412-7. 